\title{
Eckhart y la Espiritualidad de las Beguinas
}

\author{
Guillermo J. Mañón Garibay \\ Instituto de Investigaciones Jurídicas / UNAM
}

The purpose of this essay about Eckhart consist to demonstrate, how his thought had caused on account of his contact with Begins groups after his second mastery at Paris university. I want herewith refute, that Eckhart was a master of mystic, notwithstanding two his disciples, Tauler and Souse had been mystiques. I want establish which historical events had made a room for Eckhart's mystic interest.

\section{Introducción}

La intención de este texto sobre el Maestro Eckhart es mostrar cómo su pensamiento (sobre todo lo que se ha caracterizado como su intención mística) fue motivado por su contacto con los grupos de las Beguinas, principalmente después de su segundo magisterio en la universidad de París. Con esto pretendo refutar la idea que Eckhart sea un maestro de la mística, no obstante que dos de sus discipulos Taulero y Seusón hayan sido efectivamente misticos, así como hacer ver cuáles fueron los sucesos históricos que dieron lugar a su interés por la mística.

H. Denifle ha afirmado que el encuentro de Eckhart con las beguinas fue el inicio de la mistica dominica. Tal vez esto no pueda ser aceptado sin más, aunque ciertamente fueron los conventos de monjas dominicas el lugar donde se inició la mística alemana. Lo que si puede afirmarse es que fue el contacto con las beguinas $y$ monjas dominicas lo que motivo a Eckhart a desarrollar una teoría sobre la unidad del hombre con Dios (y no tanto una doctrina de la 'experiencia' mistica). No es que Eckhart haya sido un místico o un 
maestro de la mística.' Antes bien, la necesidad de predicar a monjas que vivían en un aura de raptos místicos llevó a Eckhart a ocuparse de la unidad del hombre con Dios.

El tema de la presente plática remite a la tesis de H. Denifle (editor de los sermones latinos en 1886) que dice: la forma de predicar del Maestro Eckhart responde a la necesidad histórica del cura monialum y no ha sesudas cavilaciones o a raptos emocionales como algunos romántico supusieron. Lo que quiere decir que el interés de Eckhart por la mística esta condicionado por la encomienda de la iglesia a hacerse cargo de los conventos y casas de las beguinas.

\section{Método de la exposición}

Primero explicaré un poco quienes fueron las Beguinas, después intentaré establecer una relación histórica entre Eckhart y ellas, y por último tenderé un hilo conductor entre las ideas de ambos, sin olvidar que la cuestión principal del presente ensayo es el de precisar cuál de los asuntos tratados por Eckhart está relacionado directamente con las ideas religiosas de la beguinas. La intención es hacer ver cómo trató Eckhart de darle una formulación ortodoxa a la religiosidad beguina en relación a la idea de pobreza de espiritu.

\section{Desarrollo}

Primero: Quiénes fueron las beguinas:

Las beguinas ${ }^{2}$ fueron grupos de mujeres que se formaron entre los siglos 12 y 13 , justamente al mismo tiempo en que se crearon las

\footnotetext{
I Por maestro de la mística puede entenderse dos cosas: 1) guía espiritual de sus discipulos a experimentar la unión mística y 2) teólogo fundamentandor de la posibilidad de esa experiencia mistica. En este párrafo me refiero al primer sentido y niego que Eckhart haya sido un maestro de la mística.

2 Una pequeña nota sobre los begardos: éstos fueron la contrapartida masculina de la beguinas, surgieron unos 50 años después de ellas y tomaron como modelo su religiosidad y forma de vida. De los begardos no se sabe nada, no dejaron testimonio escrito alguno. Los únicos testimonios sobre ellos son los del proceso inquisitorial en su contra. Kurt Ruh menciona que hubo historiadores que
} 
ordenes mendicantes de los franciscanos y de los dominicos. Ellas fueron, junto con los mendicantes, quienes dieron su sello a la religiosidad de la Alta Edad Media.

Las beguinas formaban pequeños grupos o comunidades de entre 3 y 12 personas, con reglas conventuales estrictas y sometiéndose a los votos de obediencia, castidad y pobreza pero sin el reconocimiento de la iglesia. Subsistían del ejercicio de un oficio como el hilado y la costura, hacer velas, etc. Como responsabilidad social habian adoptado la ayuda a los enfermos. A imitación de los franciscanos recorrían las ciudades con un saco de mendigo. Esta imagen que adoptaron les dio fama de mujeres piadosas pero al igual atrajo hacia ellas el recelo de las autoridades eclesiásticas.

Las beguinas se diseminaron en toda Europa partiendo de Holanda. Hoy día quedan aún restos en Europa del norte de las casas y granjas que habitaron. Las casas donde vivían se distinguían de las otras por tener una cruz blanca en la puerta. Acostumbraban vestir de forma muy frugal, uniformadas con hábitos blancos, café o grises, además de la habitual cofia. Por lo menos había una casa de beguinas en cada ciudad o aldea. Como ejemplo en Colonia se tiene noticia de que había 169 casas y en Estrasburgo 85. Por los informes de los cronistas de la época se calcula que el número total de beguinas en Europa alcanzaba el millón. La razón de ese enorme número se quiere ver en la prohibición de las órdenes religiosas a aceptar a más mujeres (como fue el caso de las órdenes benedictina y cisterciense), también en la pobreza e inseguridad social de la época. Pero las beguinas las conformaban grupos de mujeres nobles y acaudaladas que no tenían problema en ser aceptadas en orden religiosa alguna ni tampoco en conseguir marido o vivir desahogadamente sin él. Por eso, el principal motivo del enorme número es de indole religioso: las beguinas querian desarrollar una nueva forma de religiosidad o de vida del mensaje de Cristo, fuera de la seguridad de los muros de un convento y con la movilidad de cualquier laico.

estigmatizaron a Eckhart como begardo (ver: K. RuH: Meister Eckhart. Theologe, Prediger, Mystiker, München: Beck 1989, pág. 106). 
Se ha pensado que esta forma de vida era una especie de crítica a la iglesia ${ }^{3}$ por el hecho de no aceptar constituir una orden con reglas y votos sancionados por los funcionarios eclesiásticos $\mathrm{y}$, además, por interpretar la imitación a Cristo como vida en rigurosa pobreza, auténtica ayuda al prójimo y predicando el evangelio en plazas públicas y lengua popular (lo que ya anteriormente habían hecho los valdenses). Para entender cabalmente como esto podían constituir una crítica a la iglesia es necesario tomar en cuenta que según la mentalidad y las políticas eclesiásticas de la época no era concebible una verdadera vida religiosa sin pertenecer a una orden establecida y aceptada por la iglesia. ${ }^{4}$ Por eso, parte de las tareas asignadas a las órdenes mendicantes fue el fundar conventos donde pudieran ser recluidas las beguinas. $\mathrm{Y}$, ciertamente, muchos de los principales conventos de clarisas y dominicas se fundaron sobre los cimientos de casa de las beguinas. Un ejemplo de esto es el convento Engeltal en Nürnberg.

Pero aparte de esto, otro problema que representaban las casas "abiertas" de las beguinas era la expresión exagerada o herética de religiosidad que contagiaba al entorno. Por eso, el gran promotor del movimiento franciscano, Jacobo de Vitry, entrevió oportunamente este problema y obtuvo del Papa Honorio III el permiso para "asistirlas" espiritualmente. ${ }^{5}$ No obstante, comienzan a multiplicarse a partir de la segunda mitad del siglo 13 los indicios sobre tendencias heterodoxas o heréticas, especialmente en el norte de Francia y Bélgica. Y en el concilio de Lyón de 1274 el franciscano Simón de Tournai advierte sobre la creciente curiosidad de las beguinas por las sutilezas teológicas, por sus intentos de interpretar las escrituras pese a su ignorancia y de predicar en idioma francés en las plazas públicas.

\footnotetext{
${ }^{3}$ H. GrundmanN: "Ketzergeschichte des Mittelalters". en: Die Kirche in ihrer Geschichte, Bernd MOELLER (ed.), Göttingen: Vandenhoeck \& Ruprecht 1978.

${ }^{4}$ K. RUH: Meister Eckhart. Theologe .... cap. 7.

${ }^{5} \mathrm{~K}$. RUH: "Meister Eckhart und die Spiritualität der Beginen". en: Perspeksive der Philosophie. Neues Jahrbuch, München. Beck, 1982. tomo 8, págs. 327-336.
} 
Entre las beguinas más famosas del siglo 12 y 13 puede mencionarse a Hadewijch, Mechthild von Magdeburg y Margarita de Porete. La última de ellas fue la que tuvo más éxito con su obra. $E l$ Espejo de las Almas Simples ${ }^{6}$ fue en su tiempo traducido a cuatro idiomas (francés, inglés e italiano antiguo y latín). Kurt Ruh no conoce otro libro de espiritualidad popular con mayor difusión que el de Margarita. ${ }^{7}$ Además, la ejecución de Margarita en la hoguera le dio a su obra una enorme difusión. La obra de Margarita, en contraposición con las visiones de Hadewijch y el libro de Mechthild La Fluyente Luz Divina, es la descripción de su experiencia mística que tiene como tema central el ama desposeida de sí misma, reducida a nada, para encontrarse o unirse con Dios.

Segundo: Datos históricos importantes:

1. El 31 de Mayo de 1310 fue llevada a la hoguera Margarita de Porete por haber reincidido en herejía. El proceso fue dirigido por el dominico Guillermo de París -inquisidor general del papado para el rey francés además de su sacerdote confesor- quien también había dirigido el proceso inquisitorial contra los templarios. En el último proceso inquisitorial se volvió a encontrar en su libro El espejo de las Almas Simples los mismos errores heréticos que años antes habían provocado su quema pública. Como Margarita negó retractarse del contenido de su libro, tuvo que ser entregada a las autoridades seculares lo que significó para ella morir quemada en la hoguera.

2. De 1311 a 1313 ocupó nuevamente Meister Eckhart la plaza reservada a los dominicos no franceses en la universidad de París como maestro de teología. Años antes, de 1302 a 1303, había sido enviado por vez primera a París a ocupar esa plaza magisterial. Distinción que sólo disfruto antes y después de él Tomás de Aquino.

\footnotetext{
- Margareta PORETE: Der Spiegel der einfachen Seelen (El espejo de las almas simples). Aus dem Altfranzösischen übertragen und mit einem Nachwort und Anmerkungen von Louise Gnädinger. Zürich-München: Beck 1987.

${ }^{7}$ K. RuH: . Meister Eckhart. Theologe ... pág. 100.
} 
En su segunda estancia en París, Eckhart fue vecino del inquisidor Guillermo de París en el monasterio dominico de Saint Jacques.

3. En los mismos años (1311-1313) tuvo lugar el concilio de Vienne $^{8}$ que se ocupó de los movimientos religiosos de la beguinas y begardos así como de sus errores doctrinales. No es errado pensar que el concilio tuvo como causa la condena a la hoguera de Margarita de Porete. En 1317 fueron publicados los errores más graves y comunes de las beguinas y los Begardos. $Y$ a partir de entonces, adoptó la iglesia una nueva postura frente a estos movimientos religiosos, o sea se dio inicio a su persecución.

4. En 1317 comienza el obispo de Estrasburgo (Juan I de Zurich) la persecución de todas la beguinas y begardos.

5. En 1314 (y hasta 132201323 ) ocupa Eckhart el puesto en Estrasburgo de vicario del general de la orden de los dominicos. Lo que significaba visitar y predicar y en general asistir espiritualmente a los monasterios y conventos de las provincias teutónicas.

De estos datos pueden sacarse las siguientes conclusiones:

a) Eckhart estaba enterado acerca del proceso contra Margarita de Porete. Lo que implica que él sabía por qué se le había condenado, no sólo por haber vivido en París prácticamente durante el tiempo de su ejecución sino además porque el concilio de Vienne tuvo lugar también en tiempos de su desempeño como maestro de teología en la universidad de París.

b) Como Eckhart era vicario del general de la orden cuando comienza la persecución de la beguinas en Alemania, es seguro que él conocía a muchas de ellas y es seguro que él hiciera alusión en sus sermones a su espiritualidad y a su persecución inquisitorial.

Tercero: Relación entre Eckhart y las beguinas (Margarita de Porete):

${ }^{8}$ Vienne, ciudad en el Ródano al sur de Lyón. 
Tomado en cuenta todo lo dicho anteriormente más la afirmación de Kurt Ruh, ${ }^{9}$ quien cree que Eckhart tomó partido por las beguinas en su obra teológica y sus sermones, puede enunciarse una hipótesis, a saber: el pensamiento de Eckhart pretende dotar de un sentido ortodoxo a la espiritualidad de las beguinas.

Ciertamente, como se dijo arriba, esta es una hipótesis que ya antes fue propuesta por H. Denifle (1886), más tarde por Alois Maria Haas (1972) ( $y$ antes de Haas también de algún modo por su primer biógrafo C. Schmith ${ }^{10}$ ) y recientemente por Kurt Ruh (1978)"'. El intento del presente trabajo es el de aportar más pruebas para demostrar la verdad de esta hipótesis. La hipótesis puede ser enunciada en este trabajo de la siguiente manera: la "mística especulativa" de Eckhart (sobre todo la expuesta en sus sermones en lengua popular) tiene la intención de corregir los errores de la espiritualidad de las beguinas, sobre todo en lo que se refiere a la forma de concebir 1) el abandono o renuncia al Yo (pobreza de espíritu), 2) la unidad del hombre con Dios (el amor a Dios) y 3) la perfección humana (divinización del hombre).

Lo primero que salta a la vista para quien lea la obra de Margarita de Porete y la de Eckhart (posterior a 1312/2) son los parecidos entre las afirmaciones de ambos: comenzando con la intención de la obra (la unidad del hombre con Dios), pasando por la crítica a la razón discursiva para poder conocer a Dios (teología negativa), más la forma de concebir la pobreza espiritual y la libertad del hombre (ledic-sein y la Abgeschiedenheit) e incluso algunas de las formas de expresión (como abandono o renuncia del Yo).

\footnotetext{
${ }^{9}$ K. RuH: "Meister Eckhart und...", pág. 329.

10 Este dato sirvió a su biógrafo Carl Schmidt (1839) a pensar en dos fases del pensamiento de Eckhart: una ortodoxa (como maestro en teología) y otra herética (como predicador de la espiritualidad begina).

"No desconozco la postura de O. Langer ni tampoco la de K. Flasch y B. Mojsisch (quienes desean sacar a Eckhart de la tradición mística alemana), pero encuentro más convincentes los argumentos de Haas y Ruh al respecto.

12 Como el Liber Benedictus donde se encuentran el libro Der göttlichen Trostung (Libro del Consuelo Divino) y el sermón Vom edlen des Menschen (Del Hombre noble).
} 
Ahora bien; dentro de la obra del mismo Eckhart, si se comparan sus sermones antes de su segundo magisterio en París (como los son Rede der Unterweisung y los contenidos en Paradisus anime intelligentis) con los sermones después de su segundo magisterio, se verá que hay un cambio en la orientación e intención de su obra. En la segunda parte, Eckhart comienza a hablar del abandono total del alma, de la renuncia a la voluntad, sabiduría y posesión. No Se niega que Eckhart conserve ideas de sus obras pasadas como que la razón o racionalidad es el templo de Dios en el hombre. Pero después del segundo magisterio entiende a la razón como aquello que sustenta la unidad del hombre con Dios (chispa divina). Puede decirse que el interés de Eckhart antes "del segundo magisterio de París era puramente ético, y que éste se transforma y busca dar razón de la unidad del hombre con Dios, busca encontrar la posibilidad de una experiencia mística, después de ese magisterio.

El mejor libro para analizar la controversia entre Eckhart y la espiritualidad beguina -especialmente la de Margarita de Poretees el Liber Benedictus (de 1313), porque se conservan testimonios de beguinas sobre el efecto que esta obra ejerció sobre ellas. Entre estos testimonios están el Libro de las Hermanas de Katharinental escrito por Anna von Ramschwag o las crónicas de Ötenbacher escritas por Elsbeth von Beckenhofen y Elsbeth von Oye.

Pero analicemos las ideas de Margarita y de Eckhart más detalladamente:

1. Uno de los temas principales de Margarita es el alma adnihilata (el abandono de uno mismo o renuncia al Yo). En el capítulo 12 de su libro dice Margarita que el alma adnihilata no tiene voluntad, ni tampoco puede tenerla, ni tampoco quiere tenerla. $Y$ en el capitulo 114 dice que el alma adnihilata no tiene obra ni oprobio, no posee honor ni miedo, ni inclinación hacia el bien divino, ni sabe de alguna forma de voluntad. 
El tema del abandono de uno mismo, de lo creado y de Dios o del deseo de Dios se encuentra también en Eckhart. ${ }^{13}$ Ciertamente, en Eckhart no existe una expresión equivalente a alma adnihilata. Pero si se encuentra en el sermón Vom edlen Menschen (Sobre el Hombre honorable) la expresión ledic-sein y Abgeschiedenheit que refieren al hombre que se ha abandonado así mismo, a Dios y a todas las creaturas. $^{14}$ Eckhart describe el ser ledic sein como no desear, no saber, no tener. ${ }^{15}$

No hay que subrayar que el abandono a uno mismo, o superación de lo creado incluyendo al propio yo, es la forma tradicional y ortodoxa de entender la unión (o la condición de la unión) del hombre con Dios en toda la mística medieval: quien no renuncia a toda riqueza y así mismo, no puede entrar en el reino de los cielos. Pero también hay que tener presente, por un lado, que el tema de la pobreza provocó una fuerte polémica en la Alta Edad Media, sobre todo entre la iglesia y los franciscanos. Y, por otro lado, que Margarita de Porete, después de considerar el abandono o renuncia de forma ortodoxa, afirma que el hombre unido a Dios vive de la substancia de Dios. La unidad la concibe Margarita como participación ontológica en la misma esencia divina, o sea una divinización auténtica del hombre. Esta divinización del hombre fue considerada por Alberto Magno ${ }^{16}$ una herejía maniquea típica de los Hermanos del Libre Espíritu.

Eckhart repite mutatis muntandis lo mismo que habia dicho Margarita sobre la unidad del hombre con Dios pero hablando de la relación entre el justo y la justicia: "el hombre justo"-dice Eckhart- "no es más en sí, sino que recibe todo su ser por la justicia con la que se encuentra unida". ${ }^{17}$ Y en el sermón 15, DW I, 246, 5 ss., afirma Eckhart que lo que es propio de Dios lo es del alma unida

13 Principalmente en su sermón DW (i.e.: Deutsches Werk = Obra alemana) LII, pág. 9. cap. 5. Ahí habla Eckhart del hombre que no quiere (ver también: DW II, pág. 492. 2). no sabe (ver también: DW III. pág. 494. 4), no posee nada.

14 DW II. Pred. 48. pág. 415, 1 s.

${ }^{15}$ DW II. Pred. 52.

${ }^{16}$ compilatio de novo spiritu. 1260/1262. art. 7.

${ }^{17}$ Q 6. DW I. 103, l ss. 
a él. Seguramente esto también podría dar a pensar en un tipo de panteísmo. Pero Eckhart no escribió solamente un libro como Margarita, sino una obra teológica completa donde pudo explicar mejor sus puntos de vista. Y en su Opus Tripartitum Eckhart trató de zanjar el problema de la relación entre el hombre y Dios en la unidad mística a través de su teoría de la analogía. ${ }^{18}$ No obstante, los teólogos inquisidores de Colonia vieron en la teoría de la analogía de Eckhart un punto de crítica (así como en todo el comienzo del Libro del Consuelo Divino Q V, S. 9, 4-11, 19).

Pero además de la identidad ontológica con Dios, que derivaba para Margarita de la renuncia o desprendimiento del Yo y su voluntad, esta concepción de la pobreza espiritual fue mirada con recelo por el gran inquisidor Guillermo de París por suponer la ineficacia de las virtudes y de los sacramentos que dispensaba la iglesia. Y en verdad, en el capítulo 8 propone Margarita que el alma desposeída no precisa de ningún sacramento, virtud, e incluso gracia divina. Esta idea fue decisiva en el proceso contra Margarita y es incluso el primer artículo del escrito de condena. También el concilio de Vienne toma esta idea del libro de Margarita para ejemplificar los errores de las beguinas.

Por su lado, Eckhart, al igual que Margarita de Porete, afirmó que las "obras exteriores", como los ritos eclesiásticos y los sacramentos, son de poco o nulo valor para el alma que vive la unidad con Dios. ${ }^{19}$ El hombre justo es aquel que se encuentra en la justicia, $y$, por tanto, prescinde de los sacramentos y de la intervención eclesiástica para su salvación. Eckhart critica a quienes son cautivos de los rituales de la confesión, arrepentimiento y oración sin renunciar de su propio Yo. ${ }^{20}$ La bula papal referente al proceso inquisitorial contra el Maestro Eckhart se refiere a este desprecio por las "obras exteriores".?1

\footnotetext{
18 La teoría de la analogia es tan importante para Eckhart que en el Sermón Q. VI (DW I. 105) afirma que quien entienda su teoria de la analogía entenderá todo lo que el predica.

${ }^{19} \mathrm{LW}$ (i.e.: Lateinisches Wek = Obra Latina) Ill, núm. 561, 1.

${ }^{20}$ DW 1. Pred. 2, pág. 28, 8-10.

${ }^{21}$ Bula papal artículo 19.
} 
La idea de la pobreza espiritual (la renuncia al Yo o el abandono de si mismo) tuvo doble importancia para ambos: 1) fue el tema principal de sus obras y 2) el motivo de un proceso inquisitorial en su contra: Eckhart, al igual que Margarita de Porete, fue condenado por la inquisición. Por tal motivo, quiero dedicar el resto del escrito a presentar más profusamente la forma en que trató Eckhart de justificar esta idea en su obra.

Con la pobreza de espíritu entendida como abandono de uno mismo (ledic - sein y la abgescheiden - sein) pretende fundamentar Eckhart la unidad del hombre con Dios. Esto es lo que se ha llamado la lógica eckhartiana de la negación. ${ }^{22}$ Para explicar lo que quiere decir esto hay que hablar de la concepción del mal en Eckhart.

\section{La concepción del mal en Eckhart}

Los supuestos de los que parte Eckhart para tratar el problema del mal son los siguientes: primero, el mundo y la reflexión sobre el mundo poseen un orden y legalidad; segundo, ese orden y legalidad del mundo es algo bueno porque gracias a él es posible el ser o la vida (incluso podría afirmarse que sólo bajo ese orden determinado del mundo es posible el ser y la vida); tercero, el mal, por ser opuesto al bien, contraviene ese orden y el ser o la vida que posibilitan.

Pero ¿qué es lo que Eckhart entiende por orden del mundo? Por orden o legalidad del mundo entenderá la disposición de los entes en relación unos con otros y gracias a la cual es posible la existencia de todos como un todo o unidad. $Y$ ya en un sentido propiamente religioso agregará que esa relación no sólo es entre los entes del mundo, sino además de estos con Dios. Entonces, si el mal se concibe como opuesto al orden del mundo, querrá esto decir que con el mal hay una ruptura de la relación con el orden del mundo y, en sentido religioso, una ruptura también de la relación con Dios. Y

22 W. BeIER WALTES: Identität und Diferenz, Frankfurt am Main: Klostermann 1980. $Y$ sobre todo: W. HÜBENER: "Die Logik der Negation als ontologisches Erkenntnismittel". en: Positionen der Negativität, Hrsgd. von $\mathrm{H}$. Weinreich, München: Wilhelm Fink 1975, págs. 105-140. 
quien rompe una relación con el todo o con Dios lo hace para optar por una relación consigo mismo excluyendo a Dios y el mundo (o universo). Por eso, Eckhart concibe el mal primeramente como una negación, ${ }^{23}$ no obstante que lleva también aparejada una afirmación: Primeramente, negación del orden impuesto por Dios al universo, a través de la creación, y que posibilita el ser o la vida; y también afirmación exclusiva del propio ego. ${ }^{24}$

Pero ¿de qué tipo es esta negación y afirmación? Eckhart hablará del mal en dos sentidos: En un sentido amplio, el mal será todo aquello que se opone al orden del mundo, y éste se llamará "mal natural", o sea; el mal en la naturaleza que, en contra posición con el bien de la naturaleza, no promoverá el ser o la vida sino la destrucción del ser y la vida. De tal manera que el mal natural será todo aquello que inhiba el ser o la vida. En otro sentido estrecho, concebirá Eckhart el mal en sentido moral; o sea, como la actitud voluntaria del hombre que opta por actuar contra ese orden del mundo y a sabiendas de las leyes de ese orden del mundo. En su dimensión religiosa, el mal no sólo atentará contra el orden que ha impuesto Dios al mundo, sino a la vez será un atentado contra el mismo creador.

Aceptando esta caracterización del mal que hace Eckhart, pueden plantearse las siguientes preguntas: Si el mal es la violación de un orden natural y, además, si ese orden es la razón o posibilidad del ser y la vida ¿cómo es posible que alguien opte voluntariamente contra ese orden que también es la razón de su propia existencia? $Y$, en sentido religioso: ¿cómo es posible que el mal pretenda negar la relación con Dios cuando es éste el ser que posibilita la vida toda? Pero incluso, antes debería plantearse la siguiente pregunta: ¿cómo es posible que exista el mal, si como tal se opone a ese orden que es responsable de todo ser, incluso del "ser" o "existencia" del mal? De otro modo esta pregunta se podría formular así: ¿qué sentido puede

\footnotetext{
2.3 Tomás de Aquino: S. Th. I. II. q. 86. a. 2.

24 A lo largo de la filosofia cristiana se ha entendido siempre la afirmación egoista de uno mismo como el nucleo de la maldad moral del hombre. Comp.: San Agustin. De libero arbitrio, y Tomás de Aquino. S. Th. I-II. q. 77. a. 4.
} 
tener el mal que se opone a Dios y el mundo, y a todo lo que en principio tiene sentido? A partir de estas preguntas puede entenderse por qué Eckhart dice que el mal es pura negación.

Ahora bien; si se acepta que el mal tiene sentido o existencia, no obstante oponerse al orden del mundo y a su creador, entonces sólo podría hablarse del mal como de un intento de fundar un orden distinto a aquel con el que Dios ha dotado a su creación. En sentido religioso significaría optar por el mal, optar por uno mismo renunciando a Dios y al sentido que tiene el mundo desde él para recuperarlo desde uno mismo, o sea desde el hombre. Para Eckhart, la afirmación que entraña el mal consiste en la pretensión de ocupar el lugar de Dios. Absurda pretensión, porque implica dirigir la voluntad contra uno mismo, o sea optar voluntariamente contra el orden o fundamento del ser de uno mismo. ${ }^{25}$

El mal como negación es para Eckhart siempre un absurdo, porque es la negación de lo que tiene sentido. Por eso va a representar para Eckhart un problema interesante explicar el mal. Cuando se habla del mal natural Eckhart afirma que su principio o razón metafísica es la materia; por lo menos en un sentido tal que puede decirse que ahí donde se encuentra la materia también puede afirmarse la presencia del mal en alguna de sus formas. ${ }^{26}$ Pero como para Eckhart la materia no sólo es principio o razón del mal, sino a la vez principio del compuesto ontológico del ser individual (o sea, la materia entendida en sentido aristotélico ${ }^{27}$ ), entonces no es claro que tiene en mente Eckhart cuando postula a la materia como principio del mal.

\footnotetext{
25 Ver: I. KANT: Die Religion innerhalb der Grenze der reine l'ernunft, Erstes und zweites Stück. Darmstadt. WBG. 1998.

26 Secundo sciendum est quod. sicut ait Dionysius De divinis nominibus c. 4, bonum hominis est secundum rationem esse, malum autem quod est praeter rationem. Ratio est, quia semper bonum est a forma, malum ex materia et ex materiali. (LW II. núm. 212, pág. 178, 8-10). Comp.: LW I, núm. 35-41, pág. 212216, y LW III, núm. 551-554, pág. 481-483, y LW III, núm. 671, pág. 584, y LW IV. núm. 190, pág. 177.

27 Ver: LW I, núm. 29, pág. 498.
} 
Es necesario primeramente determinar en que sentido la materia es principio del mal, en el caso que Eckhart no haga una distinción suficiente entre mal moral y natural. Y, segundo, en el caso que así sea ( en el caso que Eckhart sí distinga suficientemente entre mal moral y natural), habrá que dirimir si Eckhart piensa en la materia como principio de ambos o establece para cada uno un principio distinto 0 , por lo menos, un sentido distinto de materia para cada uno.

Cuando Eckhart adopta a la materia como principio del mal hace uso de una larga tradición filosófica que, puede decirse, tiene su autoría primeramente en Platón, ${ }^{28}$ pero sobre todo en Plotino, ${ }^{29}$ quien escribió al respecto un tratado especialmente dedicado a la materia como principio del mal, y en Proclo, ${ }^{30}$ del quien también echa mano Eckhart no obstante que él no aceptó a la materia como principio del mal y por eso atacó duramente a Plotino. Evidentemente, Eckhart también recurre a autores cristianos $^{31}$ como Pseudo Dionisos Areopagita y sobre todo San Agustín. A través de ellos gana su solución al problema del mal un matiz propiamente cristiano, i.e. interpretando el mal como actitud moral humana y haciendo al hombre responsable de su actitud malvada.

El problema que enfrentara Eckhart, y que es una especie de conciliación entre la postura neoplatónica y la cristiana, será la de explicar la relación entre la materia, el mal y la voluntad humana. A este respecto hay que observar, que si la materia es el principio (único) del mal, entonces no parece a primera vista claro que haya la posibilidad de hacer una distinción entre el mal natural y el mal moral. Por eso, es pertinente preguntar si la materia es pensada por Eckhart como principio del mal, o simplemente como condición de posibilidad del mal. De tal modo 1) que la simple presencia de la materia indique o suponga (a manera de condición suficiente) la

\footnotetext{
28 Politicos y Timaios.

29 Enneade, 18.

30 Über die Existens des Bösek, Meisenheim am Glas: Anton Hain Verlag 1980.

31 Ver: Ps. DıONysıos: Über die göttlichen Namen. San AGuSTín: De vera relione. Tomás de AQuino: $S$. Th. I-II, q. 77, a 4.
} 
presencia del mal, o bien, 2) que la presencia de la materia represente la condición necesaria de que pueda haber mal, dando lugar sin embargo, bajo esta segunda interpretación de materia, a la actitud voluntaria del hombre para decidir entre bien y mal. A 1) se le puede llamar el sentido fuerte de la materia como principio del mal, y a 2) sentido débil de la materia como principio del mal.

Primero: hay que dirimir por qué Eckhart nombra a la materia el principio del mal.

En la concepción que tiene Eckhart de la materia combina tanto ideas platónicas como aristotélicas, lo que a primera vista puede parecer absurdo. Ya Aristóteles ${ }^{32}$ había dirigido su crítica a la concepción platónica de la materia como principio del mal, así como Proclo ${ }^{33}$ también había criticado por la misma razón a Plotino, pues para el Estagirita la materia es únicamente la razón del cambio y de la individualidad de los entes. ${ }^{34}$ Partiendo de esa interpretación aristotélica de la materia parece obvio que la materia no puede ser razón del mal cuando lo que se pretende con ella es exclusivamente explicar la individualidad de los entes y el cambio que sufren. Eckhart no parece haber conocido las objeciones de Aristóteles o de Proclo a la concepción de la materia como principio del mal (o no las toma en cuenta en sus escritos que han llegado hasta nosotros), a la vez que no parece haber distinguido claramente dos sentidos de materia (uno propiamente platónico y otro aristotélico), de tal modo que uno se aplicara exclusivamente al problema del mal y otro la composición ontológica del ente.

Primeramente, puede decirse que la materia es para Eckhart principio del mal entendida como negación, privación o defecto del ser creado, y que de ese modo no entiende Eckhart la materia en sentido aristotélico sino en un sentido más amplio como se ve en la cita siguiente, en donde Eckhart se apoya en Platón y San Agustín para hablar de la materia como principio del mal:

\footnotetext{
32 ARISTOTELES: Met. N 4 1091b 30 ss.

33 Proclo: Über die Existens..., 1980.

34 ARISTOTELES: Met. Z 7 1034a-1037a.
} 
La razón es primeramente que el mal proviene de la materia, como se dijo recientemente, ya que la materia casi no es, como dijo Agustín, o no es, como dijo Platón, además porque la materia es pura potencia o ser potencial. Potencia y acto, ser posible y ser (en acto) se oponen mutuamente. (LW III, núm. 551, pág. 481, 6-9).

Sin embargo, Eckhart utiliza también el concepto de materia en un sentido propiamente aristotélico ${ }^{35}$ pero interpretándolo de una forma negativa. Eckhart afirma en el comentario al evangelio de San Juan y citando al filósofo medieval no cristiano más importante para su pensamiento:

(...) Potencia y materia son responsables de la multiplicidad, acto $\mathrm{y}$ forma son responsables de la unidad. Todo padecimiento, privación, defecto y mal le corresponden a las cosas por razón de la materia, como dice Rabi Maimónides en el capítulo 9 del tercer libro (de su obra Guía de los Indecisos). Bien, verdad, perfección le corresponden a las cosas en razón de la forma (...)..$^{36}$

Y siguiendo esta idea de la materia como negación o principio del mal establece Eckhart su jerarquía ontológica según la cual cuanto más alto es el grado de perfección de una forma, tanto más está separada y por encima de la materia (ángeles). El hombre ocuparia un lugar intermedio dentro de esta jerarquía por poseer un alma y un cuerpo.

El problema que se puede plantear es el siguiente: Si Eckhart tiene a la materia como principio del mal y a la vez como principio ontológico del ente, entonces parecería 1) que Eckhart no distingue entre mal moral y natural, porque ambos tiene uno y el mismo principio, y, por consiguiente, parecería también que 2) el mal no

35 -Atiende por tanto a lo que dice el filósofo: Materia. forma y privación son los tres principios de las cosas de la naturaleza. Esto mismo es lo que afirma la teologia: 'tres son los que dan testimonio en el cielo" loh. 5 (...)" (LW III. núm. 441. pág. 378. 8-9).

${ }^{36}$ LW III. núm. 551 . pág. 481 1 1-3. 
tiene relación alguna con la volición del hombre, porque su origen se reduce a la materia. Y esto último es especialmente importante para Eckhart que, como pensador cristiano, reconoce la responsabilidad moral de cada persona.

Por eso, y por último, quiero hacer ver la relación que establece Eckhart entre la materia, el mal y la voluntad humana. La materia es el principio metafísico del mal, pero dentro de la antropología filosófica del Maestro Eckhart el cuerpo va desempeñar la función de la materia como principio del mal, de tal manera que el cuerpo va hacer la razón del mal del hombre.37 Pero para entender como el cuerpo puede ser principio del mal es necesario atender a la teoría del alma del Maestro Eckhart.

Eckhart, basándose en San Agustín ${ }^{38}$ y su interpretación del pecado original, distingue jerarquizando 3 facultades del alma: a) la víbora o facultad sensitiva, que es lo que tiene el hombre en común con los animales, b) la mujer o la facultad racional, pero sólo en cuanto está dirigida al mundo sensible, y c) el hombre o el intelecto (también razón superior), que es la facultad del alma capaz de aprehender a Dios. ${ }^{39}$ En razón de esta última distinción entre razón e intelecto abandona Eckhart el modelo tomista del alma ${ }^{40}$ porque Eckhart, siguiendo el principio aristotélico según el cual iguales se conocen por iguales, ${ }^{41}$ tiene que fundamentar ontológicamente en el alma la posibilidad del conocimiento de Dios. ${ }^{42}$

\footnotetext{
${ }^{37}$ Eckhart dice: " $(. .$.$) debe uno saber que el hombre se compone de dos naturalezas:$ una sensitiva y la otra intelectiva. carne y espíritu. materia y forma. Materia y carne constituyen la naturaleza sensitiva cuyas facultades están unidas a la materia, inmersas en ella y comprendidas por la carne y la materia. La razón del espiritu es la forma. que no está ni inmersa ni vinculada a órgano carnal alguno" (LW II, núm. 213, pág. 178).

38 San Agustin: De trinitate, Madrid: B.A.C. 1988, libro 12.

${ }^{39}$ LW I. n. 135, pág. 601-625.

40 O. LANGER: "Meister Eckharts Lehre vom Seelengrund". en: Grundfragen der christlichen. Mystik, Stuttgart: Bad Kannstatt. vol. 5, pág. 175.

${ }^{41}$ ARISTÓteles: Met., libro 3, B c. 41000 b, 6.

42 O. LANGER: "Meister Eckharts Lehre...", pág. 177.
} 
Correspondiendo a esta triple división de las capacidades del alma va Eckhart a distinguir entre tres tipos de conocimiento: sensitivo, racional (pero del mundo material y sensible y partiendo de la información sensorial ${ }^{43}$ ) y conocimiento de Dios. ${ }^{44}$ La distinción entre el primer y segundo tipo de conocimiento no es radical, debido a que la información sensitiva posibilita el conocimiento racional, pero esa diferencia sí será tajante entre los dos primeros y el tercero. De tal manera que Eckhart reducirá la división tripartita de las capacidades del alma y las polarizará en una división entre la capacidad inferior, por la cual el hombre conoce el mundo material (sensitiva o racionalmente), y la capacidad superior que es exclusiva para conocer a Dios. Con esta reducción tajante en dos facultades o capacidades del alma Eckhart adopta el modelo del alma de Avicena, como un conjunto doble de fuerzas, a saber: superiores e inferiores, divididas $y$ diferenciadas tajantemente las primeras de las segundas ${ }^{45}$ ). Eckhart afirma en su sermón Vom edlen Menschen (DW $\mathrm{V}$, pág. $109,7-12$ ):

Uno debe saber primeramente, y esto es algo plenamente evidente, que el hombre posee dos naturalezas: cuerpo y espiritu. (...) Por eso dice el escrito sobre los hombres: hay en nosotros un hombre exterior $y$ otro más, el hombre interior.

Partiendo de la división entre la facultad inferior y la superior del alma Eckhart describe el intelecto humano con las mismas características del intelecto divino, Eckhart dice en sermón 69 (DW IIl, pág. 169, 1-5):

Hay una fuerza en el alma que es la razón. Ella tiene desde un principio, siempre y cuando así se lo haya concedido Dios y tenga el sabor divino, cinco propiedades en sí misma. La primera es que está desvinculada del aquí y ahora. La segunda es que no tiene otra que se le iguale. La tercera que

\footnotetext{
${ }^{43}$ Ver: LW I, núm. 138, pág. 604. y DW Prd. 61. y 72

${ }^{44}$ DW III, Prd. 61, y LW I, núm. 141, pág. 608-9.

${ }^{45}$ LWI, núm. 138, pág. 605. 8.
} 
es pura y sin mezcla. La cuarta es que en sí misma es activa. $Y$ la quinta es que es una imagen.

El propósito de Eckhart es afirmar, contra Aristóteles y Santo Tomas, que el intelecto y su conocimiento esté supeditado al cuerpo o a la información de los sentidos o algún proceso de la razón inferior. Eckhart retomará en este sentido la tradición averroísta y hará de la renuncia a la influencia del cuerpo (o influencia sensitiva, o de cualquier otra facultad que tenga contacto con él) la condición del conocimiento de Dios, ${ }^{46}$ no obstante que Santo Tomas ya había defendido contra el averroísmo la unión del intelecto con todo el cuerpo $y$, debido a eso, afirmado que sin ese cuerpo sería para el alma imposible cualquier tipo de conocimiento. ${ }^{47}$

Ese conocimiento de Dios lo describe Eckhart primeramente como la participación del intelecto humano en la luz divina: ${ }^{48}$ Dios como intelecto puro o agente es luz y el hombre posee únicamente una chispa de esa luz o intelecto. Dios como intelecto agente ilumina el alma y el alma tiene la capacidad de recibir esa luz en su propio intelecto pero sin poseerla nunca. ${ }^{49}$

Lo que esta metáfora sobre la relación de la luz divina (lux) con la chispa del alma (lumen) significa es la participación del intelecto del hombre en el intelecto activo de Dios. ${ }^{50} \mathrm{Y}$ cuando el hombre ha alcanzado la iluminación divina a través del intelecto agente dice Eckhart que el hombre se ha unido a Dios (o que Dios ha nacido en el alma del hombre o que el hombre es la imagen misma de Dios). De tal manera, que para Eckhart la bondad del hombre no consiste en

\footnotetext{
${ }^{46}$ LW IV. núm. 325 pág. 421, y LW IV, núm. 206. pág. 190 ss.

${ }^{47}$ Tomás de Aquino: S. Th. I, q. 87, a. I y E. Gilson: Der Geist der mittelalterlichen PhilosophieK, München: Beck 1956, cap. 11, pág. 136.

${ }^{48} \mathrm{LW}$ IV. núm. 505 , pág. 421.

49 Eckhart afirma: "Nosotros seremos transformados' por dos razones: primero. porque la forma caduca; segundo. porque la imagen supera a la forma y es algo superior a ella. 'De claridad a luminosidad', esto significa de luz natural a luz sobrenatural y de luz de la gracia a finalmente luz de la gloria. (LW IV, núm. 508, pág. 423, 4-6).
}

${ }^{50}$ DW I. Prd. 10. pág. 162. 2. 
una conducta determinada, sino primeramente, a la manera platónica ${ }^{51}$ en un estado del alma. Ese estado del alma consiste en la iluminación del intelecto humano por el divino, y en ese estado no es posible el mal porque esa unidad implica que la voluntad personal a adoptado la voluntad divina. Y en este sentido hay que interpretar las enigmáticas palabras de Eckhart de su libro del Consuelo Divino:

Y por eso, porque Dios quiere en cierta manera que yo haya pecado, de tal forma que yo tampoco querría no haberlo cometido, porque de esa forma se cumple la voluntad divina $y$ eso es un hecho justo. De esa forma, quiere el hombre prescindir de Dios a la manera divina, y por Dios y por causa de Dios estar separado de Dios. Y esta es la forma correcta del arrepentimiento; de esta forma es la pena del pecado sin pena. Como para Dios una mala pena es pena sin pena alguna (DW V, BgT, pág. 22, 6-11).

El hombre posee por naturaleza la facultad de aprehender la luz divina o intelecto agente que emana de Dios, pero si el hombre no vuelve su atención exclusivamente al interior de su alma y desatiende toda otra influencia del cuerpo $y$ de sus facultades cognoscitivas no puede unirse o conocer a Dios. ${ }^{52}$ Esta condición es en principio exigida para todo conocimiento: Partiendo de Aristóteles ${ }^{53}$ el intelecto tiene que ser como una pizarra en blanco (tabula rasa) para estar en condiciones de conocer. ${ }^{54}$ Eckhart extrema esta condición y exige se elimine toda influencia del cuerpo, o toda influencia cognitiva de su intelecto pasivo (en forma de representación, i.e. phantasma), para poder alcanzar la unidad con Dios. De tal manera que no hay como en Averroes una transformación del intelecto pasivo en activo por Dios, sino antes bien una "destrucción" del intelecto pasivo y sus contenidos

51 Platón: Protagoras, 335a ss., 345d ss.. y Menon 77b. 78b, y Leyes V. 73 Ic: IX. 860d ss.

52 DW I, Prd. 10, pág. 163, 8-14.

53 ARISTÓTELES: Del Alma, libro 3, cap. 5, 429b-430a.

54 B. WELTE: “Der mystischer Weg des Meister Eckhart und sein spekulativer Hitergrund", en Freiheit und Gelassenheit, Meister Eckhart heute. Hrsg. Udo Kern München: Kaiser/Grünewald 1980, pág. 100. 
cognoscitivos (así como de la información sensitiva). ${ }^{55}$ Debido a esto, Otto karrer y Konrad Weiß han afirmado que la unidad del hombre con Dios que propone Eckhart es una reducción del hombre a la facultad del alma que recibe la luz de Dios. ${ }^{56} \mathrm{De}$ tal modo, que la unidad no englobaría al cuerpo del hombre, ni siquiera al alma completa, sino únicamente a la facultad del alma capaz de aprehender la luz divina.

La consecuencia de este pensamiento para la ética es considerar al cuerpo, y a todo aquello que no conduzca al conocimiento y unidad con Dios, como razón del mal. Y esto por dos razones: 1) porque el conocimiento que se obtiene a través de la información de los sentidos (o por abstracción a partir de esa información) no tiene ninguna relevancia para el conocimiento de $\operatorname{Dios}^{57} \mathrm{y}$, por esto mismo, para la unidad del hombre con Dios, y 2) porque el cuerpo impide la libre acción del intelecto por la fuerza de su concupiscencia.

Apoyándose en Maimónides expresa Eckhart esta idea en su comentario al libro de Éxodo:

En relación con esto se encuentra lo dicho por Maimónides en el libro tercero capítulo 23, a saber: "en cada hombre habitan dos criaturas; una buena y otra mala". Por criatura buena entiende él la razón y la forma en el hombre, por criatura mala la facultad sensitiva y la materia y todo aquello material en el hombre. (...) "Toda corruptibilidad, carencia, imperfección y todo pecado del hombre son consecuencia de su materia y no de su forma. El auténtico freno y subyugación de la concupiscencia, así como de toda otra

55 Ph. MERLAN: "Aristoteles, Averroës und die beiden Eckharts", en Autour d" Aristote. Récueli d'Etudes de philosophie ancienne et médiévale offer à Alenxandre Mansion. Louvain: Zeitschrift 1955, pág. 563.

56 O. KARRER: "Das Göttliche in der Seele bei Meister Eckhart", en Abhandlungen zur Philosophie und Psychologie der Religion. Würzburg: UTB 1928, Heft 19, pág. 30.

${ }^{57}$ DW II. Prd. 36b. pág. 202. 4-9. 
manifestación de la materia, se dan gracias a la forma" (LW II, núm. 214, pág. 179-180).

La concupiscencia representará en general la fuerza del cuerpo, o de la carne, que contrarresta la disposición del intelecto para unirse a Dios. ${ }^{58}$ Incluso el estado de pecado lo concibe Eckhart, también a la manera en que Platón concibió el mal, como desorden producido por la materia, lo que en el ámbito antropológico representa el dominio o gobierno del cuerpo sobre el intelecto:

'Eso fue' y es 'la condición recta del hombre', cuando la facultad sensitiva obedece a la razón inferior y se encuentra a ella subordinada, mientras que ésta última se encuentra subordinada y adherida a la razón superior y ésta a su vez a Dios, según las palabras: "Dios hizo al hombre rectamente" $($ Eccl. 7,30$)(\ldots)$ Este fue el estado de la naturaleza humana antes del pecado, el estado de inocencia.

Después que el vínculo de la razón superior del hombre y de su subordinación a Dios se destruyó por causa del pecado (...) se disolvieron todos los vínculos de las facultades del alma, tanto la facultad sensitiva como la razón inferior, de la razón superior y su dominio (...).

El estado del hombre después del pecado consiste en que el hombre sólo por la gracia divina puede rehacer su vínculo con Dios. (LW I, núm. 143-144-145, pág. 612-613).

Si el cuerpo del hombre es principio del mal, porque a través de la fuerza de la concupiscencia se trastoca el orden primigenio impuesto por Dios, entonces el camino a la unidad con Dios lo concebirá Eckhart de la misma forma en que lo enseño Platón: ${ }^{59}$ como optar

\footnotetext{
58 Naturalmente la idea del pecado como actus contra rationem ha sido utilizado en toda la tradición posterior a Platón y anterior a Eckhart, por ejemplo en el neoplatonismo: ProClo: Über die Existens..., $\$ 27$, y en la alta edad media: Tomás de AQuino: $S$. Th., II-II, q. 153, a. 2; II-II, q. 168, a. 4 .

${ }^{59}$ PLATON: Phaidon, 64a ss., 67b ss., 79c-81a.
} 
por la muerte, o como un ir muriendo, o sea irse apartando del cuerpo o materialidad. De esta forma afirma Eckhart en el sermón 8:

Nosotros loamos la muerte en Dios, con el fin de ser llevados por él a un ser que es mejor que la vida. Un ser en donde nuestra vida vive y con lo cual nuestra vida devenga ser. El hombre debe entregarse voluntariamente a la muerte y morir para con eso le sea dado un nuevo ser. (DW I, Pred. 8, 4-7).

Este enfoque del problema del mal que hace Eckhart es a primera vista una concepción muy platónica ${ }^{60}$ y poco cristiana. La solución de Eckhart al problema del mal adoptará un matiz propiamente cristiano cuando se pregunte por la responsabilidad moral del hombre, que sólo será patente en su pensamiento con relación a la superación del mal. Y nuevamente en este contexto aparecerá la lógica negativa de Eckhart como proceso que libera al hombre del mal mediante el abandono o renuncia de sí mismo y lo lleva a la unidad con Dios. Eckhart afirma tajante en su sermón 39:

(...) si ha de hacer Dios algo contigo o en ti, entonces debes primeramente reducirte a nada. (DW II, Pred. 39, pág. 256, 2-3).

La negación del hombre en este contexto ético debe ser entendida como la superación mediante la negación de un estado ontológico para alcanzar otro superior. Lo que quiere decir que para Eckhart ética y ontología forman una unidad. Este enlace de ontología y ética que hace Eckhart ha sido definido por Schönberger como una

60 Platon: Phaidon, 66b-67b. Y ver: F.P. Hager: "Die Vernunft und das Problem des Böse im Rahmen der platonischen Ethik und Methaphysik", en Noctes Romanae, Bern-Stuttgart-Leipzig: Reclam 1963, Bd. 10, pág. 15-43. Ciertamente la noción de orden y desorden como fenómenos emperejados al bién y al mal tienen también una larga tradición en el pensamiento cristiano, como por ejemplo en Tomás de AQuino: S. Th. I-II, q. 71, a. 1; Mal. q. 2, a. 9 ad 2, y q. 7, a. 1; ver: 25, 5, pero los pralelos entre Platon y Eckhart son mucho mas grandes que entre Eckhart y Tomás de Aquino. 
"ontologización" de la ética ${ }^{61}$. Y según esta ontologización de la ética, tanto la conducta justa del hombre como su conducta pecadora son resultado de un estado del hombre $y$ no de sus hábitos $o$ costumbres. ${ }^{62}$ El ser del hombre, entendido como un estar en o estar fuera de, determina la bondad o maldad de sus actos y no la conducta misma. Por eso, el requerimiento ético de Eckhart está dirigido a un dejar de ser (ente con mezcla de no-ser o materia, donde domina la concupiscencia) para llegar a ser (ente en la unidad con Dios). ${ }^{63}$

Cuando el hombre alcanza la unidad con Dios, entonces la conducta moral pasa a segundo nivel de importancia; ya que en tanto se esté en Dios se actuara adecuadamente.

La superación del mal comprende en la filosofia moral de Eckhart dos partes: una ontológica entendida como superación de la corporeidad o concupiscencia pero también como ser un éste o aquél (o sea; superación de la individualidad), y otra parte, propiamente ética, entendida como negación o abandono de uno mismo, ${ }^{64}$ como la negación del Yo que se erige como la media suprema del ser a través del querer, conocer y tener.

${ }^{61}$ R. SCHÖNENBERG: "Secundum rationem esse. Zur Ontologisierung de Ethik bei Eckhart", en: FS Robert SPAEMANN: Oikeiosis, Hrsg. R. Low, Weinheim-Freiburg, Herder 1987, pág. 255.

${ }^{62}$ Con esta posición se encontrara el Maestro Eckhart en el punto diametral opuesto a la concepción de Tomás de Aquino, pues para el Aquinante la bondad o maldad del hombre siempre remite a un hacer antes que a un ser del hombre. Ver: Tomás de AQuino, I-II, q. 72, a. $1-2$, y I-II, q. 75 , a. 1.

${ }^{63}$ La renuncia a la Diferenciabilidad del Hombre, como ser un esto u lo otro (hoc et hoc), para poder llegar a ser una idea en Dios, se ve claramente en el sermón alemán (deutsche Predigt) 46.

${ }^{64} \mathrm{~A}$ este respecto pueden mencionarse muchos lugares tanto en la obra latina como alemana de Eckhart, como: LW I, n. 130, pág. 284. 5-8, y así mismo en n. 138-139. pág. 291-292, y LW III, núm. 51, y 55, pág. 42 y 46. y LW III. núm. 480, pág. 413. y LW III, núm. 484, pág. 416. Y además, pueden también consultarse las siguientes obras de Eckhart acerca de su afirmación que el amor a uno mismo o a las creaturas (sin relación alguna a Dios) raiz y causa de todo mal, de toda carencia $\mathrm{e}$ imperfección: LW IV, núm. 187, pág. 175, y Tomás de AQuino: S. Th., I-II, q. 77. a. 4 , y I-II, q. 72 , a. 2 . 
Sólo cuando el hombre ha renunciado a su propio Yo, alcanza el estado de pobreza necesario para unirse a Dios. Y esta pobreza de espíritu es entendida por Eckhart en contraposición con Alberto Magno del siguiente modo:

El obispo Alberto (magno) dice que el hombre pobre es aquél que en todas las cosas que ha creado Dios ninguna complacencia encuentra. Y eso está bien dicho, pero yo digo mejor y entiendo la pobreza en un sentido más elevado: el hombre pobre es aquél que nada desea, nada sabe y nada tiene. (DW II, Pred. 52, pág. 488, 3-6).

Partiendo de esta cita, hay que destacar que la relevancia de la voluntad del hombre se hará patente para Eckhart siempre en forma negativa, i.e. como renuncia; ya sea renuncia a la influencia del cuerpo o renunciar al propio ego. Cuando el hombre se ha desposeído de sí mismo, puede adoptar la voluntad divina como medida de su propio querer, saber y poseer: en resumen como medida de ser bueno. Ciertamente, Eckhart afirma ya esta idea claramente en sus Sermones de juventud.

Así es con todas las cosas: Ahí dónde yo no deseo nada para mí, ahí desea Dios por mí. Ahora ipon atención! ¿Qué desea Dios por mí, cuando yo no deseo más por mi? Ahí, dónde yo he abandonado mi Yo, ahí debe Dios desear todo por mí, como cuando él desea para sí mismo, ni más ni menos, y en la misma medida en que él desea para sí. (DW V, Rede der Unterweisung, pág. 187, 6-9).

\section{Conclusión general}

Eckhart intenta explicar la pobreza de espíritu, necesaria para la unidad con Dios, de dos maneras: una epistemológica, como conocimiento de Dios a través del intelecto del hombre; y otra móral, como renuncia o abandono de uno mismo. En ambos casos la lógica negativa de Eckhart juega un papel primordial: en el primer caso, como negación de la influencia de los sentidos e intelecto pasivo; y en el segundo caso, como renuncia a la propia voluntad. 
Quiero insistir, que en sentido moral, significa pobreza de espíritu no el tener una "buena voluntad" o una "voluntad bien intencionada", sino optar por la voluntad divina a costa de la propia. Porque remitiéndonos al comienzo de esta reflexión sobre la pobreza y el problema del mal, vemos que Eckhart interpreta la materia principio del mal en sentido fuerte, i.e. como condición suficiente del mal. Lo que significa que para Eckhart sólo cuando el hombre niegue o se deshaga de la materia podrá alcanzar la unidad con Dios.

Si consideramos la intención de Eckhart de darle un sentido ortodoxo a la concepción de pobreza de espíritu de Margarita de Porete, entonces hay que terminar haciendo referencia al proceso inquisitorial en su contra.

En 1326 el obispo de Colonia, Heinrich von Virneburg, abrió un proceso inquisitorial contra Eckhart. Ese fue el único proceso inquisitorial contra un maestro de teología en toda la Edad Media. La razón del mismo no es nada clara: Karrer menciona el conflicto existente entre dominicos y franciscanos, i.e. con el proceso contra Eckhart se pretendía debilitar a la orden de los dominicos. Otra razón alude a su contacto con el movimiento religioso de las beguinas. El caso es que el 26 de septiembre de ese año se presentó una lista con 59 sentencias heréticas obtenidas principalmente de su obra en alemán. Eckhart respondió a la acusación en su famoso escrito de defensa (Rechtfertigungsschrift) donde no sólo refutó las objeciones puestas a su obra sino también puso en duda el proceso inquisitorial mismo, ya que era un privilegio de su orden el responder únicamente frente a la universidad de Paris o frente al mismo Papa. El proceso no tuvo su desenlace en Colonia sino en Avignon, donde residía el Papa Juan XXII. El 27 de marzo de 1329 fue publicada la Bula In agro dominico donde se condenaban 28 sentencias extraídas de la obra de Eckhart. Se cree que para entonces Eckhart ya había muerto y no supo de la condena definitiva de su obra. La bula menciona que Eckhart antes de su muerte abjuró de cualquier sentencia o idea que pudiera ser o sonar herética. 
Copyright of Tópicos. Revista de Filosofía is the property of Universidad Panamericana and its content may not be copied or emailed to multiple sites or posted to a listserv without the copyright holder's express written permission. However, users may print, download, or email articles for individual use. 